\title{
Reflective practice-oriented online discussions: A study on EFL teachers' reflection-on, in and for-action
}

\author{
Elif Burhan-Horasanlı ${ }^{1}$, Deniz Ortaçtepe* \\ Bilkent University, Ankara 06800, Turkey
}

\section{H I G H L I G H T S}

- Nine in-service EFL teachers' reflective discussions were examined.

- They simultaneously and collaboratively engaged in reflection on, in, and for-action.

- Online discussions served as a platform for an online community of practice.

- The level of intertextuality in their discussions depended on their training and experience.

\section{A R T I C L E I N F O}

\section{Article history:}

Received 3 December 2015

Received in revised form

23 June 2016

Accepted 3 July 2016

Available online 25 July 2016

\section{Keywords:}

Collaborative reflective practice

Reflection-on, in, and for-action

Intertextuality

Online discussions

\begin{abstract}
A B S T R A C T
This qualitative case study examined in-service EFL teachers' reflective practice oriented online discussions in a graduate course. The analysis of reflective discussions and individual interviews brought about two conclusions about the nature of reflective practice as an embedded and collaborative process. First, the results regarding participants' simultaneous engagement in reflection in, on and for-action indicate that reflective practice is an embedded process benefiting from the interplay of these three reflection types working together to lead to positive outcomes. Second, teachers benefit more from collaborative reflective practice through online discussion platforms that provide them with an online community of practice.
\end{abstract}

() 2016 Elsevier Ltd. All rights reserved.

\section{Introduction}

Reflective practice is a systematic process of problem solving through teachers' deliberate thoughtful dwelling on a specific event, incident or situation (Dewey, 1933). While researchers have tried to develop a framework to explore the quality of reflective practice in terms of breadth and depth (e.g., Bain, Ballantyne, Packer, \& Mills, 1999; Fund, Court, \& Kramarski, 2002; Lane, McMaster, Adnum, \& Cavanagh, 2014), the concept has also been enhanced with further categories: reflection-on-action, reflectionin-action (Schön, 1983), and reflection-for-action (Van Manen, 1991). A myriad of studies have been conducted in both preservice and in-service teacher education to foster teachers' reflective practice with the help of tools such as journals (e.g., Campbell-

\footnotetext{
* Corresponding author.

E-mail addresses: elifburhan@email.arizona.edu (E. Burhan-Horasanlı), denizortactepe@bilkent.edu.tr (D. Ortaçtepe).

1 Present address: University of Arizona, Tucson, AZ 85721, USA.
}

Evans \& Maloney, 1998; Moon, 2006; Uzum, Petrón, \& Berg, 2014) and portfolios (e.g., Jones, 2010; Orland-Barak, 2005). More recently, studies have investigated the use of Internet Communication Technologies (ICTs) such as blogs to promote the reflective practice of mostly novice or pre-service teachers in various academic disciplines (e.g., Bean \& Stevens, 2002; Dos \& Demir, 2013; Killeavy \& Moloney, 2010; Pedro, Abodeeb-Gentile, \& Courtney, 2012; Williams \& Jacobs, 2004; Yang, 2009). However, these studies disregarded the types of reflection in-service teachers engage in and the role of ICTs in promoting their reflective practices. In this qualitative case study we, therefore, examined in-service English as a foreign language (EFL) teachers' reflective practice oriented (RPoriented) online discussions to see the extent to which they engaged in reflection-in, reflection-on, and reflection-for-action.

\section{Theoretical framework}

\subsection{Reflective practice}

Reflective practice, also called reflection or reflective teaching, 
has been defined by first Dewey (1933), and then a number of researchers throughout the last century; thus, it is difficult to present here a single, accepted definition (Farrell, 2012; Glazer, Abbott, \& Harris, 2004; Harrington, Quinn-Leering, \& Hodson, 1996; Rodgers, 2002). Yet, Farrell's (2012) metaphor of reflection as a compass is particularly helpful. According to Farrell (2012), reflective practice "enables teachers to stop, look, and discover where they are at that moment and then decide where they want to go (professionally) in the future" (p. 7). In this process of active self-evaluation, collaboration plays a key role in gaining different perspectives through effective communication with others (Abrahamson \& Chase, 2015; Glazer et al., 2004; Ng \& Tan, 2009).

Researchers have not only suggested various definitions of the concept of reflective practice, but also examined and subdivided it into three inter-related chronological categories: reflection-on-action, reflection-in-action, and reflection-for-action (Farrell, 2012; Wilson, 2008). According to Schön (1983), "We reflect on action, thinking back on what we have done in order to discover how our knowing-in-action may have contributed to an unexpected outcome" (p. 26). That is, via reflection-on-action, the practitioner thinks about his/her previous teaching experiences and evaluates them to see if there is any opportunity or alternative to reach similar or better outcomes in the future. On the other hand, reflection-in-action, sometimes called active or interactive reflection, can be defined as teachers' conscious thinking and modification while on the job (Hatton \& Smith, 1995). This "on their feet" (Farrell, 2012, p. 12) type of reflection can help a practitioner immediately reflect on the action upon confronting it.

While reflection on-action and in-action relate to teachers' past and present exigencies, respectively, Van Manen (1991) proposes a third type of reflection, reflection-for-action, which can be defined as reflection before action or anticipatory reflection. According to Van Manen (1991), teachers not only use reflection to solve problems that happen at the time of teaching, but also consider the possible problems or situations that they may encounter in their future teaching. In other words, through reflection-for-action, reflective practitioners can identify their strengths and weaknesses, evaluate the strategies or techniques they utilize in their classrooms and thus enhance their teaching practices by overcoming anticipated problems or situations.

The quality of teachers' reflective practice has also been a concern of those researchers who have tried to develop a framework to identify the breadth and depth of reflection (Bain et al., 1999; Fund et al., 2002). While the breadth of reflection appeals to the content and/or object of the reflection depending on the practitioner's experience and context, the depth refers to the nature, form or style of the reflection engaged in (Lane et al., 2014; Rodgers, 2002). Both conventional (e.g., reflective journaling, autobiographies, action research, observations, book groups and teacher development groups) and technology-oriented tools (e.g., blogs) have been proposed to enhance the breadth and depth of teachers' reflective practice.

\subsection{The role of identity in reflective practice}

Reflective practice has also been utilized to analyze the identity construction of language teachers via tools such as diaries, narrative reflections, and mentoring meetings. According to Norton (2013), identity refers to "the way a person understands his or her relationship to the world, how that relationship is constructed across time and space, and how the person understands possibilities for the future" (p. 4). In that sense, self-image, self-esteem, self-efficacy, motivation, task perception, commitment, future perspective, knowledge, beliefs and values are some of the concepts discussed in relation to teacher identity (Day, Kington, Stobart, \&
Sammons, 2006; Gibbs, 2003; Kelchtermans, 1993). In more general terms, teachers perceive their professional identity by considering their knowledge of the subject matter they teach, their ability to communicate with students, and the training they have in order to prepare and execute lessons (Beijaard, Verloop, \& Vermunt, 2000).

Exploring teacher identity in relation to reflective practice, Urzúa and Vásquez (2008), for instance, found that engaging in future-oriented talks on metacognitive selves (e.g., awareness, intentionality, commitment, self-confidence and responsibility) enhanced novice ESL teachers' identity construction. Maclean and White (2007) also conducted a study on the impact of reflection on seven experienced and five student teachers' identity formation in their final year of a graduate level teacher education program. In the first step, student teachers' teaching practicums were recorded in videos, and then experienced teachers reflected on those recorded teaching practicums by suggesting ideas for student teachers. The findings of the study indicated that student teachers could develop their teacher identity by talking about their teaching practicums and evaluating their actions, thoughts, values, feelings and goals. Besides, the participants could also develop their identity by engaging in social interactions with experienced teachers, underlining the importance of novice-expert relationship in reflective practice.

\subsection{Technology-oriented tools to promote reflective practice}

The use of ICTs is becoming increasingly more prevalent to promote teachers' reflective practice and thus their professional development. The most common technological tools for reflective practices can be listed as chat or Internet Relay Chat (IRC), blogs, and electronic dialogue journals via e-mails. Being available in most learning management systems (e.g., Blackboard, Desire2Learn, and Moodle), online discussion forums can also be used to share, evaluate and reconstruct experience within online communities of practice (Lave \& Wenger, 1991). Developing a sense of community for reflective teachers is needed so that the interactions that trigger reflective practice can extend beyond an inward look into their teaching practices to a broader vision regarding themselves as teachers situated in a wider community of practice (Ghaye, 2011; Harford \& MacRuairc, 2008; Kabilan, 2007; Killeavy \& Moloney, 2010; Ng \& Tan, 2009; Rushton \& Suter, 2012; Yang, 2009). Rodgers (2002), in that sense, describes the role of community as "a testing ground for an individual's understanding as it moves from the realm of the personal to the public" (p. 857).

Most of the studies that explored the use of ICTs to promote reflective practice focused on novice teachers and their professional development (e.g., Jones \& Ryan, 2014; Lee-Baldwin, 2005; Pedro et al., 2012; Romano, 2008; Tsang, 2011). For instance, LeeBaldwin's (2005) study with pre-service science teachers revealed that when participants were given sufficient time, social group dynamics in online discussions helped them engage in indepth reflective thinking. Pedro et al. (2012) also examined the use of online discussions and found that clarifying, enhancing, providing evidence, and challenging were some of the reflective strategies used by the pre-service teachers in a language arts class. These studies show that online discussion platforms can be regarded as effective tools in promoting teachers' reflective practice. While all these studies focused on pre-service teachers in various disciplines and looked at the depth and breadth of their reflective practice through ICTs, there is one study that compared pre-service and in-service teachers' reflective practice in relation to local, institutional and societal dimensions (Bean \& Stevens, 2002). In their study, there was a stark difference between pre-service and in-service teachers in terms of how the former drew more on their 
personal belief systems and text references and shied away from referring to local contexts, while the latter also discussed their pedagogical decisions with more emphasis on local references. This result confirms that with more experience, teachers develop an advanced schema guiding their teaching beliefs and practices (Farrell, 2007). In that respect, it is important to see how this established schema of beliefs, roles, positionings, and practices influence in-service teachers' reflective practice in online discussions.

\section{Method}

In this qualitative case study, we explored the ways in-service English as a Foreign Language (EFL) teachers engaged in reflective practice oriented (RP-oriented) online discussions. In that sense, the present study addressed the following research question:

What types of reflection (reflection-in, on and for-action) do inservice EFL teachers engage in during their RP-oriented online discussions?

\subsection{Participants and context}

This study was conducted in the EFL Methodology course of a Teaching English as a Foreign Language (TEFL) master's program at a foundation university in Ankara, Turkey. We selected this program as our unit of analysis for the following reasons.

The MA TEFL program is offered to both international and Turkish EFL teachers who work in various universities in Turkey. The applicants of the program are required to have at least two years of teaching experience, and they are selected according to results of a verbal and a written exam which include open-ended questions and a language proficiency exam. Upon being accepted, most participants take part in the program as full-time students who take courses and write their thesis during a heavily loaded academic year. Under certain circumstances, students can also take part as part-time students in the program and complete their degree in four or six academic semesters. During the program, students enroll in various courses, which aim to improve teachers' knowledge and expertise in the field of foreign language teaching and academic research. In that sense, the courses are grouped under linguistic foundation, research-oriented and teaching-oriented courses. During the 2014-2015 academic year, there were nine participants enrolled in the EFL Methodology course of the program, offered in the fall semester (see Table 1 for demographic information of the participants). Being one of the teaching-oriented courses and requiring the students to engage in reflective practice, this course provided us with a readily available source to explore the use of online RP-oriented discussions to promote reflective practice.

One male and eight female students whose ages ranged between twenty-five and thirty-five participated in this study. All of them were native speakers of Turkish and started learning English as a foreign language either at primary or secondary school. The majority of the participants took part in the MA program as fulltime students and worked as English teachers at state universities in various cities in Turkey. Only one of the participants attended the program as a part-time student and worked for a foundation university.

\subsection{Data collection}

Online RP-oriented discussions (reflective discussions hereafter) were collected via the EFL Methodology course the participants took in their master's program. Throughout the course, in order to encourage them to share their ideas and experiences in teaching, the participants were asked to write several reflection papers under various topics such as a) their experiences as a language learner, b) their experiences as a language teacher, c) post-method era, d) teacher as a cultural mediator, and e) teaching with technology. As being aware of their own intuitive knowledge and considering problems from different perspectives are two important aspects of reflective practice (Farrell, 2012; Loughran, 1996; Pedro et al., 2012), the first two tasks were assigned so that the participants could reflect on the two sides of the education process: teachers and learners. These two tasks were also important as reflective practice requires "thinking about the beliefs and values related to English language teaching, and seeing if classroom practices are consistent with these beliefs and values" (Farrell, 2015, p. 4). For the last three reflections, recent articles on these issues were assigned by the course instructor to be used as a reference point (see Appendix A for the list of assigned readings). Some guiding questions (e.g., Do you agree or disagree with any one of the researchers? What are the points you can accept or you resonated with in the readings? What is your take on the articles?) were also posted by the instructor for each reflective discussion.

Participants first posted their own reflection papers under separate threads on Moodle. As for the discussion sessions, the participants were asked to 1) read at least three of their colleagues' reflections, 2) write at least a comment/question for each on Moodle, and 3) answer the questions addressed to their own original post or reply to each other's comments. The instructor of the course, the second author of this study, followed the guidelines provided by Glazer et al. (2004) to promote collaborative reflective practice among the students. She worked as a facilitator and encouraged an online community that was driven by the participants' needs. In that sense, the topics listed above were assigned as starting points, but the participants could discuss any issues as long as it was related to the general topic. The instructor showed little teacher-presence in order not to interfere with the self-sustaining nature of the reflective discussions. Instead, at the end of each discussion, she provided a summary sheet to the participants, pointing out the common themes/patterns that emerged in the

Table 1

Demographic information of the participants.

\begin{tabular}{|c|c|c|c|c|c|c|}
\hline Participants & Sex & Age & Age of learning english & Undergraduate degree $^{a}$ & Years of teaching experience & Teaching certificates \\
\hline P \# 1 & Female & 25 & 11 & ELL & At least 2 & - \\
\hline P \# 2 & Male & 35 & 6 & ELL & More than 10 & - \\
\hline$P \# 3$ & Female & 28 & 11 & LING & $5-10$ & CELTA \\
\hline P \# 4 & Female & 26 & 10 & ELT & $3-5$ & CELTA \& DELTA \\
\hline P \# 5 & Female & 28 & 12 & ELT & $5-10$ & CELT \\
\hline P \# 6 & Female & 27 & 12 & ELT & $3-5$ & CertTESOL \\
\hline P \# 7 & Female & 28 & $12-13$ & ELT & $5-10$ & ICELT \\
\hline P \# 8 & Female & 28 & 11 & ELT & $3-5$ & - \\
\hline P \# 9 & Female & 27 & 11 & ELT & $3-5$ & - \\
\hline
\end{tabular}

a ELL: English Language and Literature, LING: Linguistics, ELT: English Language Teaching. 
discussions and provided explanations to any unclarified issues.

In addition to the online discussions of the participants, we decided to have interviews with them to see evidence of professional growth that occurred in the reflection process. The first author of the study conducted the semi-structured interviews so that the participants would not feel threatened by the presence of the course instructor and share their experiences more openly. In the first part of the interviews, there were purposefully chosen questions from the participants' five reflection papers and the discussion sessions. The number of the questions varied in the first section as these questions came from their interactions in the online discussion forum (See Appendix B for sample questions). As a result of this, the length of the total interviews ranged from $25 \mathrm{~min}$ to $80 \mathrm{~min}$. The second part of the interviews included 5 open-ended questions adapted from Bennett-Jackson's (2010) study, to evaluate the overall thoughts of the participants regarding these reflective discussions (see Appendix C). All participants preferred to conduct the interviews in English despite the fact that they were given the freedom to choose either English or Turkish or code-switch whenever they felt the need.

\subsection{Data analysis}

We first prepared hard copies of data gathered from reflection papers, the discussion sessions, and the interviews. Later, reflection papers and the discussion sessions were categorized separately for each individual and every single comment or question the participants directed to and received from each other were also listed in each individual's folders. For the interviews, we first completed the verbatim transcription by writing every single detail that showed up in speech such as repetitions, incomplete utterances and affective expressions (i.e., laughs). Also, during the transcription stage, we took notes about the preliminary themes that participants talked about so as to build a bridge between data collection and analysis as suggested by Patton (2002). Then, printed copies of reflection papers, discussion sessions, and transcribed interviews were compiled. In order to provide anonymity, we gave codes to each participant (e.g., Participant 1 [P \# 1]) according to the alphabetical order of their names.

Upon compiling pages of raw data, we decided to apply inductive thematic analysis so as to complete the bottom-up feature of the analysis stage (Boyatzis, 1998). The steps of thematic analysis were defined as preparation, pattern recognition, creating a code, and comparing themes (as adapted by Ortaçtepe, 2012). We first read the reflection papers and transcribed interviews several times in order to create codes. Next, we categorized the naturally occurring codes under broader themes which were then color coded and organized under the three reflection types. According to Murphy (2013), "although they [reflection on, in and for action] are neatly circumscribed within boxes, the boundaries, in reality, are less exact and will probably tend to merge with one another" (p. 183).
Therefore, at this stage, we benefited from Wilson's (2008) temporal categorization of reflection to distinguish the reflection types. Past situations and experiences were categorized under reflectionon-action, participants' awareness on present conditions was listed under reflection-in-action, and future plans and intentions of teachers were categorized under reflection-for-action. Each researcher conducted the data analysis separately and then discussed the emerging themes and codes to see if there were any discrepancies. The triangulation of the data sources (using both online discussions and the interviews) helped us see if what they have produced in their reflective discussions were supported by their accounts revealed in their interviews as well as if there were any inconsistencies in the findings. By triangulating with multiple data sources and analysts we managed to overcome "the skepticism that greets singular methods, lone analysts, and single-perspective interpretations" (Patton, 2002, p. 556).

\section{Findings}

\subsection{Reflection-on-Action}

Reflection-on-action requires teachers to look back on their past experiences and evaluate them by sharing their ideas and perceptions. The participants in this study frequently engaged in this retrospective reflection under two themes: learner and teacher identity (see Table 2).

Throughout their reflective discussions, participants reflected on their own learner identities in relation to motivation, personal characteristics, autonomy and language learning experiences. First of all, motivation was a common issue across five participants as they reflected on its contribution to themselves as language learners. Participant \# 7 (P \# 7) described herself as a really hardworking student who studied hard in order to catch up with the other students during high school. She was highly motivated as she thought learning a language was really prestigious. P \# 6 also defined herself as a motivated learner as she stated:

From the point of view of Lightbown and Spada, I can say that I am a good English learner as I am somehow a self-conscious and motivated learner. I always try to create an environment or situation where I am exposed to language and practice it. The other way of improving English was keeping a diary and a travel journal in English and I have always tried to find some ways to go to English-speaking countries as I believe that one of the best ways to learn a language is in its natural environment. I wanted to learn it for myself around the world, meet new people, learn new cultures and visit my relatives abroad.

While motivation was one of the factors the participants reflected on in relation to their own language learning processes, a second issue that came up in the reflective discussions in relation to

Table 2

Themes and codes for reflection-on-action with their frequencies.

\begin{tabular}{|c|c|c|c|c|c|c|c|c|c|c|}
\hline \multirow[t]{2}{*}{ Themes } & \multirow[t]{2}{*}{ Codes } & \multicolumn{9}{|c|}{ Participants } \\
\hline & & 1 & 2 & 3 & 4 & 5 & 6 & 7 & 8 & 9 \\
\hline \multirow[t]{4}{*}{ Learner Identity } & Motivation & 2 & 2 & - & - & 1 & 2 & 3 & - & - \\
\hline & Personal characteristics & - & - & - & - & - & 2 & - & 2 & 2 \\
\hline & Autonomy & 3 & - & - & - & 5 & - & 1 & - & 3 \\
\hline & Language learning experiences & 6 & 7 & 5 & 3 & 5 & 5 & 8 & 3 & 5 \\
\hline \multirow[t]{2}{*}{ Teacher Identity } & Teaching processes & 4 & 5 & 4 & 3 & 5 & 6 & 8 & 5 & 4 \\
\hline & Professional development & 6 & 5 & 5 & 5 & 6 & 5 & 5 & 5 & 5 \\
\hline
\end{tabular}

Note: The frequencies reflect how many times participants wrote comments about each code. 
their learner identity was personal characteristics. P \# 9 attributed the challenges she faced in learning English to her language teacher, while P \# 8 discussed how she tried to overcome those challenges that led to her speaking anxiety. Yet, in both cases, teacher-centered and drilled based classes were the main problems they encountered:

She was unable to interact with her students, care for their needs and capacities. The characteristics of my English teachers did not change a lot even in the following stages of my adventure. Our classes were mostly teacher-centered and their lessons were basically centered on the textbook and doing lots of drilling exercises that were really boring and colorless. That unrest caused me to have some prejudgments about English and English teachers. (P \# 9).

\section{P \# 8 also mentioned similar concerns:}

Our classroom was mostly teacher centered, therefore, I and my classmates did not have enough chances to practice speaking and listening skills and that situation led me to lack selfconfidence in myself and I became shy about making mistakes in public. My shyness still prevails and I still haven't overcome it.

Related to the challenges they faced while learning English, learner autonomy was yet another issue discussed both implicitly and explicitly throughout their reflective discussions. For instance, $\mathrm{P} \#$ 8, in order to overcome her shyness, made a to-do-list to encourage her participation and fostered the learning process by engaging in speaking activities with her peers. P \# 5 also noted taking responsibility for her language learning by talking to native English language speakers:

During the summer time, we were spending the whole summer in Fethiye [a touristic town in Turkey] and it was the first time when I spoke to a native speaker. I realized that the way Turkish people speak English is totally different from the way a native speaker does. As soon as we went back home, I made my father set up some English channels on TV like BBC, CNN and Discovery Channel.

The participants' language learning experiences were not limited to learning English but extended to their third language learning processes. For instance, when P \# 6 was talking about the role of motivation, she mentioned how she could learn another language easily and how successful she was at her third language, German, as well. P \# 2 also shared her positive experience in learning Italian as below:

My teacher was excellent. I was already in love with the target language; however, the way the teacher treated us and taught the language enhanced my learning. The teacher only talked in the target language. Moreover, she was sharing lots of stories she experienced during her stay in Italy and these stories were encouraging me as well as increasing my enthusiasm about learning Italian.

As seen in these excerpts, participants reflected on their learner identities by sharing their language learning experiences in relation to the classroom atmosphere, the profile of their language teachers, as well as the techniques applied by their teachers and themselves throughout their second and third language learning processes. It was also interesting to see that they drew from their own language learning experiences in their own teaching practices with the techniques they utilized in their own classrooms and the language learning strategies they suggested to their own students. In that sense, the participants' reflection-on-action not only revolved around their learner identities but also extended to their teacher identity especially in relation to the tension between their early careers and professional development. More specifically, looking back at their early careers and comparing their current-selves with the novice ones was the common issue across participants. P \# 7 stated that:

When I first started teaching, I wanted to be like the teacher in the movie "Dead Poets Society" and touch the lives of my students by helping them become more self-confident, responsible and conscious learners as well as teaching English. As a more experienced teacher now, I have the same enthusiasm but more realistic goals.

By looking at her teaching experience and identifying her role as a teacher in the classroom, she realized that as time went by she was becoming more professional by reshaping her attitudes towards her students. P \# 9 also shared her teaching experience as a novice teacher when she worked for a public university in the east of Turkey as below:

I had some other problems related to the attitudes of students towards English and English language teachers. The students really had resisted me when we first met because they thought that my job was to assimilate them. They were not aware of the importance of speaking a second language, neither in social life nor in academic life. In order to overcome that difficulty, a few colleagues and I decided to translate students' Kurdish fairy tales first into Turkish, and then into English. We could finally compile those stories in a book and worked on English via those materials. That way, I could reach the students and gain their attention. At the end, we were successful in teaching English language. I believe that those difficulties helped me profoundly to strengthen my teaching and my teacher identity. I remember leaving the classes crying, but I believe that those were the times that helped my teaching profession a lot; I wouldn't be as I am right now without experiencing those situations.

The participants also discussed the influence of RP-oriented online discussions on their professional development especially in regards to issues such as their role as cultural mediators, the use of technology, and their teaching pedagogy. Since participation in the online discussions was a requirement for their EFL Methodology course, they first perceived these posts as assignments rather than opportunities to reflect on their teaching practice, but in time, as they shared and discussed more, their attitudes shifted towards seeing them as a platform for professional development. For instance, in regards to being a cultural mediator, P \# 7 stated that each institution should provide similar opportunities for teachers to come together and discuss their experiences with each other.

It was good to see, I mean, it is not just me, but we all have some kind of lack of, I mean, confidence in our abilities. And we also shared ideas about what to do about this topic, so my suggestion was having exchange programs for teachers within an institution but of course this is something I can't achieve. This is what institutions should consider for teachers' professional development.

Considering these findings, it can be concluded that participants of this study engaged in reflection-on-action by defining their 
learner and teacher identities. When asked to evaluate reflective discussions, participants stated that they had the chance to go through the processes they had as learners and teachers. They claimed that seeing these two perspectives from their very own experiences developed and enhanced their teaching practices while they also gained insights into strategies and teaching techniques used by their classmates.

\subsection{Reflection-in-Action}

According to Murphy (2013), reflection-in-action can be regarded as teachers' awareness on current conditions, thus takes place at the time of teaching. It can also be described as teachers' reflection on the present situations and conditions (Wilson, 2008). Although the participants of this study were not actively teaching at the time of the study (as they were full-time MA students for that one year except one of them), they could still reflect on their teacher beliefs and practices as EFL teachers (see Table 3).

As shown in Table 3, under the theme teacher beliefs, participants first shared their roles as EFL teachers and then discussed their strength and weaknesses. The participants believed that they acted as facilitators/motivators in the classrooms. In order to motivate their students, they counseled them about international exchange programs such as Erasmus or Work \& Travel. A related role, in that sense, was being cultural mediators as they emphasized the importance of blending students' own cultural practices with the target culture in their classroom. Participant \# 3, \# 8 and \# 9 also stated that one of the most important roles of teachers was to develop critical thinkers. P \# 3 and P \# 8 believed that their students were mature enough to critically evaluate political issues and share their ideas with each other. P \# 3 reported on her role as below:

I like talking about political rights, justice and injustice issues. And, as they are experiencing kind of imposition by government, they like talking about it. ... I want them to be a critical thinker; that's why political issues can be a good way, talking about political issues can be a good way to make them criticize what is happening in Turkey or in the world in general.

On the other hand, P \# 9 stated that she generally brought some real-life issues (e.g., environmental problems), into the classroom and wanted students to solve these problems by brainstorming. However, she did not prefer talking about political issues because she believed that those issues were risky and the students may have had different ideas.

As reflection-in-action can be defined as a stop-and-think process in which a teacher can virtually evaluate the situation and make a decision about it (Van Manen, 1991), the participants also reflected on their strengths and weaknesses in relation to their teaching beliefs. Creating a friendly and meaningful atmosphere especially with the use of warm-up activities was one of their strengths as they believed that creating a stress-free atmosphere enhanced student learning and increased their motivation. For instance, P \# 2 stated:

I allocate some time to discussion sessions about some topics such as music or football, in which students can share their ideas with ease. During these sessions, I do not correct my students' grammar mistakes in order not to make them feel under pressure or stressed and my students are always aware that they will never be judged by me, their teacher, about their ideas or suggestions presented throughout the classroom discussion sessions.

Similarly, they stated that defining their relationship with the students was a strength as they believed that trying to be friendly, not a friend of their students would be a facilitating factor in their classroom management. On the other hand, excessive teacher talking time was seen as a weakness as it could decrease students' motivation. One of the participants considered her lack of knowledge on utilizing technology as a weakness in her teaching practice as she believed that appealing the contemporary students required the utilization of technological tools.

One of the features of reflection-in-action, according to Eraut (1995) is that, it specifically relates to the teachers' very own teaching context. Thus, an important finding of the study is that teachers' engaged in reflection-in-action by pointing out their practices, which were shaped according to their teaching contexts. For instance, participants stated in their reflective discussions that they chose the methods according to their students' needs. Since their students were assessed based on grammatical accuracy and language skills, the participants chose Eclectic Method by combining bits and pieces from several methods including Grammar Translation Method and Communicative Language Teaching. In addition, one of the participants took the advantage of her social environment by assigning tasks in which the students had to record interviews with native speakers of English visiting Istanbul. To sum up, even though the majority of the participants were not actively teaching during the year they spent as graduate students, they could still reflect on their teaching practices by discussing their roles, strength and weaknesses in relation to their particular teaching contexts.

\subsection{Reflection-for-Action}

According to Uzum et al. (2014), "Reflection-for-action may entail a teacher's making note of the weaknesses in a lesson and proposing an action to address these problems in future lessons" (p. 5 ). In the present study, evidence of teachers' reflection-on-action was seen in their future intentions to overcome their weaknesses in their teaching. In that sense, they engaged in reflection-foraction in three distinct orientations: a) improving their own teaching practices, b) enhancing their students' learning and, c)

Table 3

Themes and codes for reflection-in-Action and their frequencies.

\begin{tabular}{|c|c|c|c|c|c|c|c|c|c|c|}
\hline \multirow[t]{2}{*}{ Themes } & \multirow[t]{2}{*}{ Codes } & \multicolumn{9}{|c|}{ Participants } \\
\hline & & 1 & 2 & 3 & 4 & 5 & 6 & 7 & 8 & 9 \\
\hline \multirow[t]{3}{*}{ Teachers' beliefs } & Defining teachers' roles & 4 & 4 & 6 & 3 & 6 & 6 & 7 & 5 & 7 \\
\hline & Strengths & 2 & 4 & 3 & 2 & 4 & - & 4 & - & - \\
\hline & Weaknesses & - & - & 3 & - & - & 3 & - & 2 & - \\
\hline \multirow[t]{2}{*}{ Teaching Practices } & Methods & 6 & 10 & 8 & 5 & 11 & 8 & 11 & 7 & 6 \\
\hline & Classroom management techniques & - & 5 & - & 3 & 4 & - & - & - & 3 \\
\hline
\end{tabular}

Note: The frequencies reflect how many times participants wrote comments about each code. 
contributing to their institutions at large (see Table 4).

As shown in Table 4, several issues came up in relation to their plans for the future as they had the chance to observe each other's teaching practices through the reflective discussions and analyze the missing parts in their teaching. For instance, $P$ \# 3 realized that she never used mnemonics as P \# 1 did in her teaching to enhance students' vocabulary knowledge. She reported that:

I think vocabulary is one of the cores of language learning, and this was one of the things that I struggled actually at the very beginning because students tend to memorize the Turkish translations. No matter what I do in classroom, I tell them to write the English definitions, examples etc. but it is not very realistic for them. They don't do it. So I try to do as much vocabulary activities as possible in classroom like preparing vocab cards or preparing games. However, my repertoire in this sense is a bit limited. That's why I asked P \# 1 about this to have more activities. It was a genuine question to be honest and he explained it but I need further reading ...

A similar attempt was seen in the interview sessions of $\mathrm{P} \# 1, \mathrm{P} \#$ 5 and $P$ \# 8, as well. Upon seeing P \# 9 sharing her to-do list strategy to overcome students' affective barriers, they decided to use similar techniques with their own students in their future teaching.

Improving their teaching skills was inevitably linked to their reflections for enhancing students' learning as well as contributing to their institutions. For instance, they not only became aware of the importance of using warm-up activities and sharing course objectives to gain students' attention and to motivate them but also stated their willingness to use them in their future practices. P \# 1 reported that:

I already used activities about movies and songs in my classes; however, I have not explained the course objectives to his students, so I found P \# 8's suggestion about sharing course objectives really effective to raise students' awareness about the expected learning goals and I really would like to implement it in my future teaching.

All the participants except P \# 5 and \# 8 declared that they shared their own learning experiences and processes with their students to establish rapport with them. After the reflective discussions, both P \# 5 and P \# 8 mentioned that they would like to share their experiences with their future students. For instance, $\mathrm{P} \#$ 8 stated that:

... this online discussion created an awareness. Because most of the people told that they share their learning experiences with their students. Actually, this is something that I haven't done up to now. So, I agree with them. It might be a good idea to share our experiences. I didn't share my experience, but I understood them.
Similarly, they also (re)defined the role of technology in language classroom by reading how their classmates utilized technology via some activities or tools. The majority of the participants were eager to implement Wikis in their future practices to enhance students' learning environment. Besides, they also reflected on the effectiveness of the activities they once utilized and found ineffective in their classes. Seeing their classmates applying similar activities (e.g., error correction by writing students' mistakes on the board), they understood that they might benefit from those activities again according to the classroom dynamics of their prospective students.

As for their intentions to further contribute to their institutions, P \# 7 planned to suggest her administrators cultural exchange programs for preparatory school students. She reported that:

If students are given awards like those who get the highest grade will get the chance to go abroad for one week, or two weeks whatever, it might be a great opportunity and it might be very motivating rather than just passing the exams and going to their departments. Therefore, I will suggest it to my administrators, but still I have doubts about its acceptance.

Secondly, for the sake of increasing students' awareness towards the target culture, one of the participants indicated his desire to start movie clubs in his institution. That way, he believed that he could create cultural relevance between the target culture and his students' own cultures. The third intention for institutional change was detected in the assessment procedure. Two of the participants reconsidered the grading system of their online course book exercises. They considered the possibility of making those activities voluntary in order to foster autonomy among learners. For instance; P \# 5 stated that:

I thought that they didn't use it [online coursebook exerises] because they are not autonomous learners, but I think we should find some ways to make them more autonomous rather than forcing them. So, P \# 3's comment helped me think about it and maybe we could change this system and I will discuss it with my administration and my colleagues.

Last but not least, participants stated their desire to ask for peer observation sessions in their institutions in order to enhance their professional development. P \# 9 reported in her interview that sharing ideas among her colleagues and getting feedback from them would enhance her teaching. All these findings indicate that their comments in relation to reflection-for-action all highlighted their roles as agents of change as they all made plans to change their teaching practices by enhancing students' learning processes with strategies and raising student motivation with teaching techniques. They reconsidered the old activities they had previously used, and decided to reutilize those after hearing about the other

Table 4

Themes and Codes for Reflection-for-Action and their Frequencies.

\begin{tabular}{|c|c|c|c|c|c|c|c|c|c|c|}
\hline \multirow[t]{2}{*}{ Themes } & \multirow[t]{2}{*}{ Codes } & \multicolumn{9}{|c|}{ Participants } \\
\hline & & 1 & 2 & 3 & 4 & 5 & 6 & 7 & 8 & 9 \\
\hline \multirow[t]{6}{*}{ Teachers as agents of change } & Enhancing learning processes with strategies & 4 & - & 4 & - & 6 & - & 7 & - & 8 \\
\hline & Raising student motivation & 3 & 3 & 3 & 7 & 11 & 6 & 3 & 6 & 6 \\
\hline & Reviving old activities & - & - & 3 & - & 3 & 3 & - & 3 & 3 \\
\hline & Integrating culture into teaching & - & 3 & 3 & 3 & 3 & 4 & 4 & 4 & 8 \\
\hline & Appealing to digital natives with tools of technology & 4 & - & 3 & 2 & 5 & 6 & 4 & 4 & 5 \\
\hline & Offering suggestions for institutions & 3 & - & - & - & 4 & - & 3 & - & 4 \\
\hline
\end{tabular}

Note: The frequencies reflect how many times participants wrote comments about each code. 
participants' experiences. Participants also shared their intention to integrate both target culture and the students' own cultures into their teaching practices. As teachers of a technology era, they also planned to enhance their teaching by implementing tools of technology to appeal to their students, so called digital natives (Prensky, 2001). Last but not least, participants indicated their intentions to improve their teaching environment by offering suggestions to the administrators at their institutions.

\section{Discussion}

The findings of the present study indicated that the in-service EFL teachers enrolled in the MA TEFL program spontaneously engaged in reflection in, on, and for-action. The reflective discussions not only provided a venue that they could share their experiences as language learners and teachers (as shown in their reflection-on-action) and identify their strengths and weaknesses (as shown in reflection-in-action) but also helped them gain insights into their future practices by benefiting from each other's experiences. The breadth and depth of their reflective discussions resulted from their interactions with each other where they drew not only upon the literature but also upon their own knowledge and experience to critically examine different pedagogies in relation to teaching and learning. These results lead to two important conclusions about the nature of reflective practice as an embedded and collaborative process. First, teacher's reflective practice is an embedded process benefiting from the interplay of reflection on, in and for-action working together to lead to positive outcomes in teachers' practices and professional development at large; and second, teachers benefit more from collaborative reflective practice through online discussion platforms that provide them with an online community of practice.

\subsection{Reflective practice as an embedded process}

According to Wilson (2008), "reflecting on past and present actions has an inherent and tacit recognition that there may be scope for improving future performance" (p. 182). In this study, the findings not only indicated that the teachers engaged in all three reflection types (in, on and for-action), but that the former two reflection types worked as a catalyst to trigger reflection-for-action, and thus, improved their professional development (see Fig. 1).

The participants engaged in reflection-on-action mostly by defining their own learner and teacher identities in relation to their past experiences while their engagement in reflection-in-action depended on their description of current teaching practices. These findings supported Maclean and White's (2007) study in which pre-service and in-service teachers' joint reflection on practicum videos shaped the former group's teacher identity by

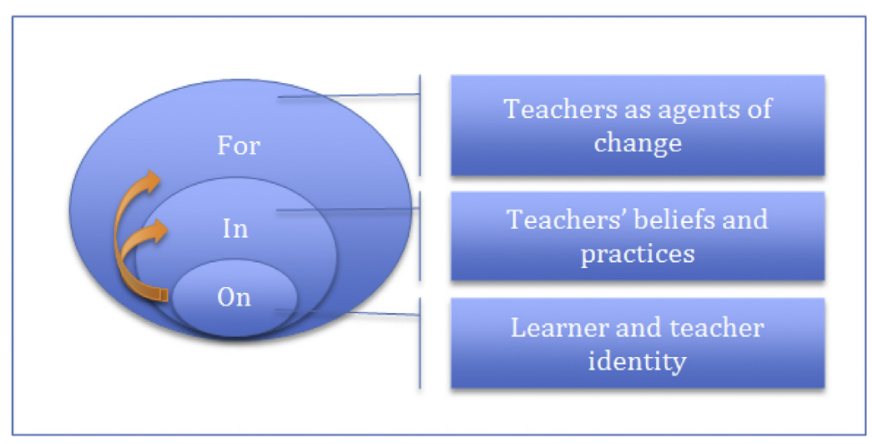

Fig. 1. Reflective practice as an embedded process. enabling them to discuss their actions, thoughts, values, feelings and goals with their more experienced counterparts. According to Moon (2006), reflection in and on-action should be considered as parts of a continuum rather than a dichotomy, one requiring a quicker, more unconscious thought while the other provides more time to act more slowly and consciously. Our findings confirm her suggestion because when it comes to issues that required a more conscious retrospective look (e.g., identity), the participants engaged in reflection-on-action, as opposed to those issues that are more within their immediate presence (e.g., teaching practices), in regards to which reflection-in-action was more prominent.

Participants' reflection-for-action, on the other hand, relied on the issues they brought up in regards to their institutions, as they shared their intentions regarding changes related to their teaching practices. In that sense, the participants' beliefs on their present exigencies which were difficult to change and rooted in context (reflection-in-action), were not only mirrored images of their learner and teacher identities (reflection-on-action), but also sources of factors that enabled them to extend beyond their immediate contexts and situations to consider improvements in their teaching practices (reflection-for-action). According to Van Manen (1991), reflection-for-action:

enables us to deliberately think about possible alternatives, decide on courses of action, plan the things we need to do and anticipate the experiences we and others may have as a result of expected events or of our planned actions. (p. 101).

This study's findings suggest that such a course of action based on anticipated experiences of events can only be made possible by critically evaluating the present conditions (reflection-in-action) and taking a retrospective look at previous experiences (reflectionon-action). Murphy (2013) also states that teachers get accustomed to certain anomalies in their classrooms as they become more experienced. That way, they create frames for similar situations in their mind and apply these frames when they encounter such conditions. This connection between reflection-in-action and foraction is even more clear as "there should be some conscious consideration of what is happening, how effective the behavior is, and whether there might be more appropriate alternatives" (Wilson, 2008, p. 179). In the present study, this relationship was reflected in how the participants drew from both their colleagues' and their own past and present experiences to develop expectations about their future practices by projecting a variety of scenarios and then examining what might happen. Therefore, we conclude that reflective practice has an embedded nature in which these three types of reflection interplay with each other (Farrell, 2007), intertwined, in flux, overlapping and multifaceted (Murphy, 2013; Uzum et al., 2014; Wilson, 2008), rather than functioning as three separate processes with a linear relationship among them.

\subsection{Reflection as a collaborative practice}

Another important conclusion of this study relates to the way online discussions enabled the participants to create an online community of practice where they could engage in collaborative reflective practice. According to Abrahamson and Chase (2015), a collaborative reflective practice is one in which "human speech supplements an artifact's back talk" (p. 373). Ghaye (2011) explains this aspect of reflective practice as social learning, where people learn from and with others. In the present study, the breadth (i.e., numerous comments and questions on various issues) and depth (i.e., the level of intertextuality) of reflective discussions as shown in Tables 2-4 and in the excerpts, resulted from the teachers' being 
in-service teachers and graduate students at the same time, so that they could not only share their own knowledge and experience but also draw from the literature to talk about themselves, make suggestions to others and support their claims. We believe that this intertextuality in their interactions led to collaborative reflective practice.

In a very broad sense, intertextuality refers to "how texts draw upon, incorporate, recontextualize and dialogue with other texts" (Fairclough, 2003, p. 17). Among the researchers who developed a framework to identify the depth of reflective practice, Fund et al, (2002) refer to this type of intertextuality as linking while Bain et al. (1999) call it reasoning, both referring to the connections made between previous teaching experience and knowledge gained from the literature. However, in this study, the intertextuality within the reflective discussions was not limited to connections made between participants' own experiences, tacit knowledge, course readings and other sources. Instead, similar to Admiraal and Wubbels' (2005) student teachers' reflections which were "developed in interaction with other students' comments and with other written texts" (p. 323), this study's participants specifically drew examples from each other's posts to support a claim, evaluate a teaching method, challenge each other's ideas or even explain a change they were planning to make in their teaching. We believe that the two roles these participants had as in-service teachers and graduate students played a significant role in this latter form of intertextuality that enabled them to engage in collaborative reflective practice. Similar to Pedro et al.'s (2012) study, our participants used the online platform as an online community where they could share their experiences and knowledge with each other and consider future scenarios for their teaching processes. In that sense, this study proposes that intertextuality is a major component of collaborative reflective practice (e.g., Admiraal \& Wubbels, 2005; Strong-Wilson, 2006) because of "the unending embeddedness of our own stories within those that seem also to belong to others" (Rolling, 2004, p. 551).

As mentioned earlier, the participants reported not enjoying the reflective discussions early in the semester as they were a part of the course requirements. Yet the collaborative nature of the discussions led to a change in their attitudes in time; the participants stating that they came to understand the importance of reflective practice by jointly constructing new meanings about their practice (i.e., interacting with their classmates, learning about each other's experiences, and paying attention to each other's comments and questions and suggestions for their teaching practices) within a community of practice. This finding is also in line with Glazer et al. (2004), who claim that being a part of a supportive group of colleagues helps "identify and address professional practice-related issues and challenges" and thus leads to positive attitudes towards professional development (p. 37). Kabilan's (2007) study also underlines the role of collaboration in reflective practice since "when shared with other members of a learning community, the individual's thoughts and experiences are collaboratively maximized" (p. 698).

The influence of previous experience and accumulated knowledge on reflection is also supported by Tsang's (2011) study, which required first and third year students of oral health and dentistry to have RP-oriented online group discussions. The results revealed that the first year students did not regard these platforms as useful tools for their learning while the third year students perceived the discussions as educationally valuable. Bean and Stevens' (2002) study also support our findings as they also found that experience changes the choice of content (i.e., beliefs, text references, pedagogical decisions) and dimension (i.e., local, institutional and societal) in reflective discussions. We believe that participants all being in-service teachers with at least two years of experience contributed to their positive attitudes: as Farrell (2007) has mentioned, novice teachers may not be able to engage in reflectionin-action, as they may not have access to a large body of tacit knowledge in teaching. Overall, the results confirm that experience builds up the content of the reflective practice, that is "what is talked about" (Ghaye, 2011, p.45), and, as presented in this study, influences the breadth and depth of reflective practice.

\section{Conclusion}

In this study, we explored the RP-oriented online discussion forums of nine in-service EFL teachers in terms of the three reflection types (reflection-in, on and for-action) they engaged in. The findings revealed that participants' teaching experience and their studies as graduate students contributed to the level of intertextuality and led them to engage in collaborative reflective practice by simultaneously reflecting on, in, and for-action. Thus, we propose that online RP-practice oriented discussions, as in the successful utilization of blogs (Dos \& Demir, 2013; Williams \& Jacobs, 2004; Yang, 2009), can serve as a platform where EFL teachers collaboratively reflect on their own and colleagues' beliefs and practices within an online community of practice.

One of the limitations of this study was that all but one of the participants did not teach during their master's program: the outcome of their reflective practices, especially the participants' intentions for the changes in their future teaching practices, have not been examined. A further study might therefore be conducted to see if the participants will put into practice their intentions in the future when the participants start teaching again in their institutions. Future studies might also be carried out with in-service teachers who continue teaching throughout the time of the RPstudy to explore the actual changes in their future practice. Another study might be conducted with both pre-service and in-service teachers in online discussion platforms so that the novice-expert interactions can be observed within a reflective community of practice.

The findings of the study might benefit teacher education and teacher development programs by suggesting that online discussion platforms can be utilized as effective tools to promote both novice and experienced EFL teachers' reflective practices. By providing threaded online discussions to EFL teachers as a support for face-to-face classes, teachers' reflective practices can be enhanced in such a way that they can evaluate their teaching practices by relating their experiences both inside and outside the language classroom. Teacher educators and trainers might be encouraged by this study's findings to set up tasks for online discussions in a way that each task can facilitate the three embedded processes of reflective practice (see Appendix D for two samples of reflective tasks). Online discussion forums can be designed to promote collegiality and mutual support so that pre-service and/or in-service teachers can engage in teacher interaction and collaboration within a professional learning community.

\section{Appendix A. List of assigned readings for the reflection papers}

\section{Reflection 3: reflecting on post-method pedagogy}

Bell, D. M. (2007). Do teachers think that methods are dead? ELT Journal, 61 (2), 135-143.

Kumaravadivelu, B. (2006). TESOL methods: Changing tracks, challenging trends. TESOL Quarterly, 40 (1), 59-81.

Prabhu, N. S. (1990). There is no best method - why? TESOL Quarterly, 24 (2), 161-176. 
Reflection 4: reflecting on culture in teaching

Cook, V. (2002). Language Teaching Methodology and the L2 User Perspective. In V. Cook (Ed.), Portraits of the L2 user (pp. 325-343). Clevedon: Multilingual Matters.

Sowden, C. (2007). Culture and the 'good teacher' In the English language classroom. ELT Journal, 61 (4), 304-310.

\section{Reflection 5: reflecting on the use of technology}

Blake, R. J. (2011). Current trends in online language learning. Annual Review of Applied Linguistics, 31, 19-35.

Cambre, M., \& Hawkes, M. (2004). Toys, tools \& teachers: The challenges of technology. Maryland: Scarecrow Education.

Koehler, M. J., \& Mishra, P. (2009). What is technological pedagogical content knowledge? Contemporary Issues in Technology and Teacher Education, 9 (1), 60-70.

Salomon, G., \& Perkins, D. (2005). Do technologies make us smarter? Intellectual amplification with, of and through technology. In R. J. Sternberg, \& D. D. Preiss (Eds.), Intelligence and technology (pp. 71-86). Mahwah, NJ: Lawrence Erlbaum Associates.

\section{Appendix B. Interview questions for the 1st part}

Sample interview questions for Participant \#6 regarding her reflection \# 1.

1) P \#6, your question to $P \# 3$ was about her compulsory elective language course. You believe that making a language course compulsory may have possible negative effects on learners but $P$ \#3 stated a counter comment. She says that it did not lower her desire to learn a language. Does this counter statement affect your belief in this case?

2) You asked P \#4 a question about strategies that she uses to analyze learner differences. She states that she uses a learning styles/preferences questionnaire most of the time after spending some time with students to get to know them. She also observes them in pair/group or individual activities. What do you think about the strategies and would you like to implement them in your class?

\section{Appendix C. Common interview questions for the 2nd part (adapted from Bennett-Jackson, 2010)}

1. As you reflect over the period of time, what were some of your most outstanding learning moments throughout your reflection papers and the discussion sessions?

2. How interactive do you think the discussion forums were to improve your reflective practice? Have you suggested any websites or videos to support your suggestions or ideas?

3. Do you have any clarifications to make for the themes or categories generated throughout your reflection paper and the discussion processes?

4. Now that you have seen the themes and categories generated from my observations, what are your overall thoughts regarding how your epistemological beliefs impacted your reflection?

5 . What (if anything) will you change about the way you teach in the future?

\section{Appendix D. Sample reflective tasks}

Task 1. Defining yourself as a language learner.

Reflection-on-Action Give us a profile of yourself as a language learner. For example, think about your own personal experiences with learning other languages and reflect on what worked for you and what did not.

Reflection-in-Action What are your characteristics as a learner? Do you consider yourself a "good language learner?" (See Lightbown and Spada, chapter 3 for a list of these characteristics.) How might your experience as a language learner inform your teaching practice? Is there any relationship?

Reflection-for-Action What similarities/differences do you see between your experience as a learner and the learners you encounter/might encounter in your current or future classes?

Task 2. Teacher as a cultural mediator

Reflection-on-Action

How have you, as a language teacher, integrated culture into your classroom so far?

Reflection-in-Action What do you understand by cultural awareness? In what ways do the cultural aspects of the English language take place in your classrooms?

Reflection-for-Action What else can be/should be done to raise intercultural awareness as part of the ELT curriculum in your country/context?

\section{References}

Abrahamson, D., \& Chase, K. (2015). Interfacing practices: Domain theory emerges via collaborative reflection. Reflective Practice, 16(3), 372-389.

Admiraal, W., \& Wubbels, T. (2005). Multiple voices, multiple realities, what truth? Student teachers' learning to reflect in different paradigms. Teachers and Teaching: Theory and Practice, 11(3), 315-329.

Bain, J. D., Ballantyne, R., Packer, J., \& Mills, C. (1999). Using journal writing to enhance student teachers' reflectivity during field experience placements. Teachers and Teaching: Theory and Practice, 5(1), 51-73.

Bean, T. W., \& Stevens, L. P. (2002). Scaffolding reflection for preservice and inservice teachers. Reflective Practice, 3(2), 205-218.

Beijaard, D., Verloop, N., \& Vermunt, J. D. (2000). Teachers' perceptions of professional identity: An exploratory study from a personal knowledge perspective. Teaching and Teacher Education, 16(7), 749-764.

Bennett-Jackson, D. (2010). In D. Dissertation (Ed.), The impact of science teachers' epistemological beliefs on authentic inquiry: A multiple case study. Waco, TX, USA: Baylor University.

Boyatzis, R. E. (1998). Transforming qualitative information: Thematic analysis and code development. Thousand Oaks, CA: Sage.

Campbell-Evans, G., \& Maloney, C. (1998). An analysis framework for reflective writing. Australian Journal of Teacher Education, 23(1), 29-38.

Day, C., Kington, A., Stobart, G., \& Sammons, P. (2006). The personal and professional selves of teachers: Stable and unstable identities. British Educational Research Journal, 32(4), 601-616.

Dewey, J. (1933). How we think: A restatement of the relations of reflective thinking to the educative process. Boston: D.C. Heath \& Co.

Dos, B., \& Demir, S. (2013). The analysis of the blogs created in a blended course through the reflective thinking perspective. Educational Sciences: Theory \& Practice, 13(2), 1335-1344.

Eraut, M. (1995). Schön shock: A case for reforming reflection in action. Teachers and Teaching: Theory and Practice, 1(1), 9-22.

Ghaye, T. (2011). Teaching and learning through reflective practice: A practical guide for positive action (2nd ed.). New York, NY: Routledge.

Fairclough, N. (2003). Analysing discourse: Textual analysis for social research. New York, NY: Routledge.

Farrell, T. S. C. (2015). Reflective teaching. Annapolis Junction, MD: TESOL Press.

Farrell, T. S. C. (2012). Reflecting on reflective practice: (Re)visiting Dewey and Schön. TESOL Journal, 3(1), 7-16.

Farrell, T. S. C. (2007). Reflective language teaching: From research to practice. London, UK: Continuum Press.

Fund, Z., Court, D., \& Kramarski, B. (2002). Construction and application of an evaluation tool to assess reflection in teacher training courses. Assessment and Evaluation in Higher Education, 27(6), 485-499.

Gibbs, C. (2003). Explaining effective teaching: Self-efficacy and thought control of action. Journal of Educational Enquiry, 4(2), 1-14.

Glazer, C., Abbott, L., \& Harris, J. (2004). A teacher-developed process for collaborative professional reflection. Reflective Practice, 5(1), 33-46.

Harford, J., \& MacRuairc, G. (2008). Engaging student teachers in meaningful reflective practice. Teaching and Teacher Education, 24(7), 884-1892.

Harrington, H. L., Quinn-Leering, K., \& Hodson, L. (1996). Written case analyses and critical reflection. Teaching and Teacher Education, 12(1), 25-37. 
Hatton, N., \& Smith, D. (1995). Reflection in teacher education: Towards definition and implementation. Teaching and Teacher Education, 11(1), 33-49.

Jones, E. (2010). A professional practice portfolio for quality learning. Higher Education Quarterly, 64(3), 292-312.

Jones, M., \& Ryan, J. (2014). Learning in the practicum: Engaging pre-service teachers in reflective practice in the online space. Asia-Pacific Journal of Teacher Education, 42(2), 132-146.

Kabilan, M. K. (2007). English language teachers reflecting on reflections: A Malaysian experience. TESOL Ouarterly, 41(4), 681-705.

Kelchtermans, G. (1993). Getting the story, understanding the lives: From career stories to teachers' professional development. Teaching and Teacher Education, 9(5/6), 443-456.

Killeavy, M., \& Moloney, A. (2010). Reflection in a social space: Can blogging support reflective practice for beginning teachers? Teaching and Teacher Education, 26(4), 1070-1076.

Lane, R., McMaster, H., Adnum, J., \& Cavanagh, M. (2014). Quality reflective practice in teacher education: A journey towards shared understanding. Reflective Practice, 15(4), 481-494.

Lave, J., \& Wenger, E. (1991). Situated learning: Legitimate peripheral participation. New York, NY: Cambridge University Press.

Lee-Baldwin, J. (2005). Asynchronous discussion forums: A closer look at the structure, focus and group dynamics that facilitate reflective thinking. Contemporary Issues in Technology and Teacher Education, 5(1), 93-115.

Loughran, J. (1996). Developing reflective practice. Learning about teaching and learning through modeling. London, UK: Falmer Press.

Maclean, R., \& White, S. (2007). Video reflection and the formation of teacher identity in a team of pre-service and experienced teachers. Reflective Practice, $8(1), 47-60$.

Moon, J. A. (2006). Learning journals: A handbook for reflective practice and professional development (2nd ed.). New York, NY: Routledge.

Murphy, J. (2013). Reflective teaching: Principles and practices. In M. Celce-Murcia, D. Brinton, \& M. A. Snow (Eds.), Teaching English as a second or foreign language (pp. 613-629). Boston, MA: National Geographic Learning and Heinle.

Ng, P. T., \& Tan, C. (2009). Community of practice for teachers: Sensemaking or critical reflective learning? Reflective Practice, 10(1), 37-44.

Norton, B. (2013). Identity and language learning: Extending the conversation change $\left(2^{\text {nd }}\right.$ ed.). Bristol, UK: Multilingual Matters.

Orland-Barak, L. (2005). Portfolios as evidence of reflective practice: What remains 'untold'. Educational Research, 47(1), 25-44.
Ortaçtepe, D. (2012). The development of conceptual socialization in internationa students: A language socialization perspective on conceptual fluency and social identity Newcastle-upon-Tyne. UK: Cambridge Scholars Publishing.

Patton, M. Q. (2002). Qualitative research and evaluation methods (3rd ed.). Newburry Park, CA: Sage Publications.

Pedro, J., Abodeeb-Gentile, T., \& Courtney, A. (2012). Reflecting on literacy practices: Using reflective strategies in online discussion and written reflective summaries. Journal of Digital Learning in Teacher Education, 29(2), 39-47.

Prensky, M. (2001). Digital natives, digital immigrants. On the Horizon, 9(5), 1-6.

Rodgers, C. R. (2002). Defining reflection: Another look at John Dewey and reflective thinking. Teachers College Record, 104, 842-866.

Rolling, J. H. (2004). Messing around with identity constructs: Pursuing a poststructural and poetic aesthetic. Qualitative Inquiry, 10(4), 548-557.

Romano, M. E. (2008). Online discussion as a potential professional development tool for first-year teachers. Technology, Pedagogy and Education, 17(1), 53-65.

Rushton, I., \& Suter, M. (2012). Reflective practice for teaching in lifelong learning. Maidenhead: Open University Press/McGraw Hill.

Schön, D. A. (1983). The reflective practitioner: How professionals think in action. London: Temple Smith.

Strong-Wilson, T. (2006). Bringing memory forward: A method for engaging teachers in reflective practice on narrative and memory. Reflective Practice, 7(1), $101-113$.

Tsang, A. K. L. (2011). Online reflective group discussion-connecting first year undergraduate students with their third year peers. Journal of the Scholarship of Teaching and Learning, 11(3), 58-74.

Urzúa, A., \& Vásquez, C. (2008). Reflection and professional identity in teachers future-oriented discourse. Teaching and Teacher Education, 24(7), 1935-1946.

Uzum, B., Petrón, M., \& Berg, H. (2014). Pre-service teachers' first foray into the ESL Classroom: Reflective practice in a service learning project. TESL-EJ, 18(3), 1-15.

Van Manen, M. (1991). The tact of teaching: The meaning of pedagogical thoughtfulness. Albany, NY: SUNY Press.

Williams, J. B., \& Jacobs, J. (2004). Exploring the use of blogs as learning spaces in the higher education sector. Australasian Journal of Educational Technology, 20(2), 232-247.

Wilson, J. P. (2008). Reflecting on-the-future: A chronological consideration of reflective practice. Reflective Practice, 9(2), 177-184.

Yang, S. (2009). Using blogs to enhance critical reflection and community of practice. Journal of Educational Technology \& Society, 12(2), 11-21. 